\title{
Spontaneous Isolated Pericardial Tamponade Associated with Warfarin
}

\author{
Recep Akgedik ${ }^{1}$, Zeki Yüksel Günaydın², Deniz Kızılırmak³ ${ }^{3}$ Yusuf Emre Gürel² \\ ${ }^{1}$ Department of Pulmonary Medicine, Ordu University Faculty of Medicine, Ordu, Turkey \\ ${ }^{2}$ Department of Cardiology, Ordu University Faculty of Medicine, Ordu, Turkey \\ ${ }^{3}$ Department of Pulmonary Medicine, Fatih University Faculty of Medicine, Ankara, Turkey
}

To the Editor,

An 83-year-old female patient was admitted to the emergency department with progressive dyspnea and orthopnea for 3 days. She was discharged with warfarin therapy (5 $\mathrm{mg}$ per day) due to pulmonary embolism 5 months previously. On admission she was orthopneic and tachypneic. Her arterial blood pressure was $90 / 60 \mathrm{mmHg}$ and heart rate was $115 / \mathrm{min}$ with sinus rhythm. On cardiac auscultation, S1 and S2 intensity were decreased, and pathologic murmur and pericardial friction were not observed. Other physical examination findings were unremarkable. An increased cardio-thoracic ratio was revealed on chest X-ray (Figure 1a). Decreased QRS voltage and sinus tachycardia was evaluated on electrocardiogram. The internalised normalised ratio (INR) level was 8.6 and the prothrombin time was 70 seconds. Haemoglobin was determined to be $11.1 \mathrm{~g} / \mathrm{dL}$. The other laboratory findings were normal. An emergency thoracic computed tomography (CT) scan was performed to exclude recurrent pulmonary embolism, and surprisingly showed a massive pericardial effusion (Figure 1b). However, echocardiography revealed severe pericardial effusion that was compressing the right ventricle. Therefore, vitamin $\mathrm{K}$ and fresh frozen plasma infusion were administered promptly. As a result, the INR was decreased to 1.4 and $800 \mathrm{~mL}$ haemorrhagic fluid was drained percutaneously $(\mathrm{P} / \mathrm{S})$ with the apical approach. The patient's blood pressure, orthopnoea and dyspnoea improved dramatically. There was no other source of bleeding except haemopericardium. Consequently, the cardiac tamponade in our patient, secondary to haemopericardium, was considered to be the result of the incorrect dosage of Warfarin.
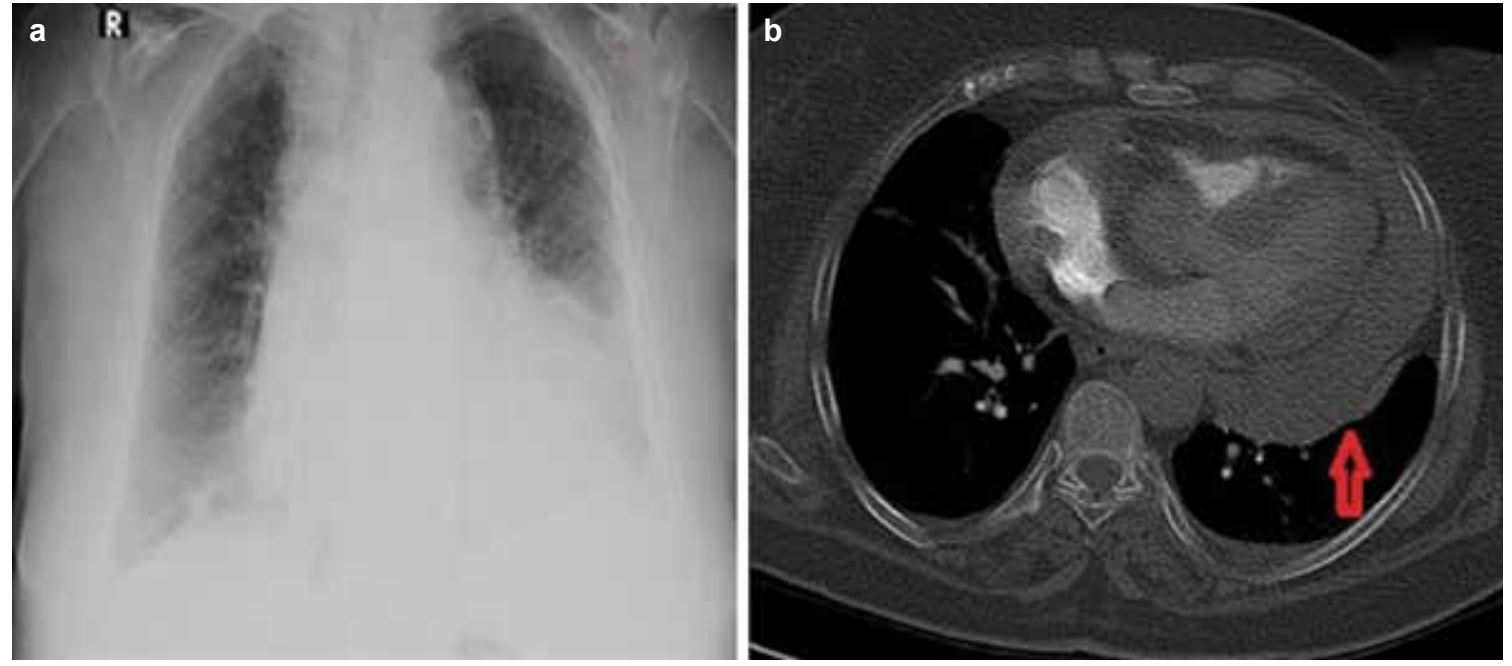

FIG. 1. a, b. Increased cardio-thoracic ratio due to pericardial effusion on chest X-ray (a). CT scan of chest showing large pericardial effusion (see arrow) (b)

Address for Correspondence: Dr. Zeki Yüksel Günaydın, Department of Cardiology, Ordu University Faculty of Medicine, Ordu, Turkey

Phone: +90 5057075782 e-mail: doktorzeki28@gmail.com

Received: 03.06.2014 Accepted: 12.08.2014 • DOI: 10.5152/balkanmedj.2015.15395

Available at www.balkanmedicaljournal.org

Akgedik R, Günaydın ZY, Kızılırmak D, Gürel YE. Daily melatonin levels in women with systemic lupus erythematosus.

Balkan Med J 2015;32:135-6. 
On control echocardiography, there was no recurrence of pericardial fluid and the patient was discharged on the $5^{\text {th }}$ day.

Cardiac tamponade is a life-threatening emergency condition. It is an acute type of pericardial effusion in which fluid accumulates in the intrapericardial space. This creates a mechanical pressure in the cardiac chambers which disrupts cardiac filling. (1). The common causes of pericardial effusion resulting in tamponade are pericarditis, malignancy, acute myocardial infarction, congestive heart failure, collagen vascular diseases, end stage renal disease, viral and bacterial infections (1). Cardiac tamponade secondary to haemopericardium is rarely seen and occurs with traumatic and non-traumatic causes. Non-traumatic causes are less common and associated with a number of conditions such as malignancy, infection, uraemia or coagulopathy (2). Today, warfarin sodium is still the most commonly used agent for anticoagulant therapy. The risk of spontaneous bleeding in patients using warfarin is less than $10 \%$, whereas the risk of bleeding into the pericardial space is less than $1 \%$ (3). Echocardiography, which is the diagnostic test of choice, evaluates the haemodynamic consequences and guides transcutaneous drainage; CT is useful for further workup. These methods are superior to echocardiography for anatomical information, characterisation of the effusion, and providing information about the adjacent structures (2). The primary treatment of pericardial tamponade is pericardiocentesis.. Echocardiography-guided pericardiocentesis has been shown to be a safe and effective method which can be performed at the patient's bedside (4). Isolated haemopericardium and cardiac tamponade secondary to warfarin are seen very rare. Haemorrhagic cardiac tamponade should be excluded in patients on warfarin with unexplained hypotension and excessive anticoagulation. Close monitoring of INR level is very important in the management of patients, especially in the elderly receiving warfarin treatment (5).
Ethics Committee Approval: Ethics committee approval was received for this case.

Informed Consent: Written informed consent was obtained from the patient for the publication of this case report and any accompanying images.

Peer-review: Externally peer-reviewed.

Author contributions: Concept - R.A.; Design - Z.Y.G.; Supervision - Y.E.G.; Resource - D.K., R.A. Materials Z.Y.G., D.K.; Data Collection\&/or Processing - R.A.; Literature Search - Y.E.G.; Writing - Z.Y.G.; Critical Reviews - D.K.

Conflict of Interest: No conflict of interest was declared by the authors.

Financial Disclosure: The authors declared that this study has received no financial support.

\section{REFERENCES}

1. Yüksel V, Hüseyin S, Okyay A, Gürkan SC, Gür Ö, Canbaz S et al. Management of pericardial effusion by subxiphoidal pericardiostomy in adults. Türk Göğüs Kalp Damar Cerrahisi Dergisi 2012;20,492-6.

2. Ertaş F, Polat N, Yıldız A, Oylumlu M, Ülgen MS. Anticoagulant-induced hemopericardium with tamponade: A case report and review of the literature. JCEI 2013;4:229-33. [CrossRef]

3. Braiteh F, Plana JC. Spontaneous haemopericardium with subacute cardiac tamponade in a patient with lung cancer receiving coumadin. QJM 2009;102:575. [CrossRef]

4. His DH, Krishnamurthy M, Ryan GF, Luo P, Woodlock TJ. Successful management of hemopericardium and cardiac tamponade secondary to occult malignancy and anticoagulation. Exp Clin Cardiol 2010;15:e33-5.

5. Christensen TD. Self-management of oral anticoagulation therapy methodological and clinical aspects. Dan Med Bull 2011;58:B4284. 